\title{
International migration desires related to subjective well-being
}

\author{
Ruohong Cai ${ }^{*}$, Neli Esipova ${ }^{2}$, Michael Oppenheimer ${ }^{3,4}$ and Shuaizhang Feng 5
}

\author{
* Correspondence: \\ ruohongc@princeton.edu \\ ${ }^{1} 411$ A Robertson Hall, Woodrow \\ Wilson School of Public and \\ International Affairs, Princeton \\ University, Princeton, NJ 08544, USA \\ Full list of author information is \\ available at the end of the article
}

\begin{abstract}
Previous research on the determinants of international migration has largely focused on objective factors, such as income. We instead use subjective well-being (SWB) to explain international migration desires, an expressed willingness to migrate. We find that individuals with higher SWB have lower international migration desires. At the individual level, the SWB-migration relationship appears to be more robust than the income-migration relationship. At the country level, national average SWB better indicates international migration desires for rich countries, while income performs better for poor countries. We thus demonstrate the feasibility of employing subjective measures to study at least one aspect of an important social outcome, migration.
\end{abstract}

JEL codes: $F 22, \mathrm{O} 15,131$

Keywords: Subjective well-being; International migration desires; Income; Logistic regression

\section{Introduction}

The determinants of international migration, such as income difference, relative deprivation, climate variation, and social conflict, have been broadly studied (Clark et al. 2007; Stark and Taylor 1989; Naudé 2010; Feng et al. 2010; Feng and Oppenheimer 2012). While income maximization is often viewed as a major determinant of international migration, maximizing income alone may not lead to utility maximization, since other factors such as weather, culture, and the crime rate are also considered by potential migrants in making a final migration decision (Borjas 1989). However, many of these migration determinants are unobserved and interrelated (Massey et al. 2010). For instance, due to income transfers, individuals with a family member abroad, a factor known to facilitate international migration, may have a higher income level than individuals lacking such a link (Massey et al. 1993). Even if we are able to disentangle and measure these unobserved factors, it would be unclear how to quantify their aggregated effects on migration. In this study, we look for a comprehensive measure that can capture many of the aggregate effects of multiple migration determinants, including both the effect of income difference and the effects that income difference fails to capture as indicated by Borjas (1989).

As a measure of the quality of life, subjective well-being (SWB) may be a plausible candidate for such a measure. Oswald and Wu (2010) found a link between SWB and several objective factors, indicating that SWB contains "genuine information about the 
quality of human lives". Therefore we expect that SWB may capture some objective factors which influence migration decisions. Furthermore, many unobserved determinants of migration may alter a potential migrant's subjective perception of well-being, and thus could be captured by SWB which reflects both objective and subjective conditions (Diener 1984). Freeman (1978) raised a similar point that satisfaction, ${ }^{1}$ an important component of SWB, depends on some unobserved factors. Otrachshenko and Popova (2014) also noted that life satisfaction may be used as a proxy for unobserved factors. Some studies use SWB as a predictor, where it can help explain human behavior such as quitting a job, child development, or even wearing a seatbelt (Clark 2001; Park 2004; Goudie et al. 2012). To test the validity of using SWB to explain international migration, another human behavior, we estimate the effects of SWB on international migration desires.

Using actual migration data might generate different results, as a desire does not necessary translate into action due to obstacles such as policy and physical barriers. But a link between actual migration and individual SWB is not investigated here due to lack of access to follow-up interview data. Fortunately, migration intentions and aspirations have been shown to be good predictors of future actual migration behavior (Van Dalen and Henkens 2008 and 2013; Creighton 2013) and in the Result section we test the validity of using migration desire for the purposes here. While many researchers use the term "migration intention" to describe future possible migration behavior, we use the term "migration desire" since the main survey question we used is not about planned actions. However, our results are also robust to a question related to migration intention (see Appendix A for more details).

Literature has found that the level of SWB may be affected by many factors. In a review paper of the determinants of SWB, Dolan et al. (2008) summarized that "poor health, separation, unemployment and lack of social contact are all strongly negatively associated with SWB." Income is expected to be a major determinant of SWB, since higher income would allow an individual to purchase more goods and thus help enhance utility. Although the Easterlin paradox suggests that higher income does not increase happiness at the country level (Easterlin 1974), researchers have posed challenges to Easterlin's finding in recent years. For instance, using the Gallup World Poll data, Deaton (2008) demonstrated a log-linear relationship between average SWB and GDP per capita across countries. Stevenson and Wolfers (2008) found a positive relationship between GDP per capita and SWB across countries. Kahneman and Deaton (2010) found that high income improves evaluation of life but not emotional well-being. Researchers also claimed that an income-SWB link might not be consistent across the income levels. For instance, Diener and Seligman (2004) indicated that the income-SWB link may be less significant when income exceeds certain level. However, using the Gallup World Poll data, Stevenson and Wolfers (2013) studied the incomeSWB link at both individual and country level and found a significant and consistent income-SWB link for both poor and rich countries.

A positive income-SWB relationship is important for our analysis. If SWB were not associated with income, given that income is an important determinant of migration, it would be hard to justify that SWB is a comprehensive measure of the determinants of migration. Simpson (2013) made a similar point that "the relationship between income and happiness is central to the study of happiness and migration." However, another 
concern may arise: since income is associated with both migration and SWB, a SWBmigration link may be due to the confounding factor - income. We are unconcerned about this endogeneity in this study since we do not attempt to find a causal relationship between SWB and migration, but rather a correlation between two. In other words, we do not investigate what causes migration; instead, we look for a comprehensive indicator for it. In a similar study focusing on the effects of happiness on emigration rate, Polgreen and Simpson (2011) also had a research scope: "the correlation between happiness and migration, instead of the direction of causality." In sum, while SWB and income are highly correlated, SWB is expected to capture many unobserved factors that income may not be able to capture, and thus may be a more comprehensive indicator of migration than income.

Previous studies mostly focused on how actual migration experience affects SWB. For example, while migration experience by a household member increases the life satisfaction of the members who do not migrate (Cárdenas et al. 2009), immigrant's life satisfaction may decrease after migration or be lower than residents in destination countries (De Jong et al. 2002; Bartram 2011). Simpson (2013) presented a detailed literature review on the relationship between happiness and migration. Some measures which may be similar to SWB have been employed to study their effects on migration. For instance, for a survey conducted in Texas, respondents with "a lot of joy" from their neighborhood are less likely to move in the next year, as compared to respondents with "little or no joy" (Bucchianeri 2007). In Latin America, people satisfied with their economic situation are less likely to migrate (Graham and Markowitz 2011), and people with high life satisfaction have less intention to migrate abroad (Chindarkar 2014). In Central and Eastern Europe, people dissatisfied with life have a higher intention to migrate (Otrachshenko and Popova 2014). These results indicate that SWB and migration may be correlated in certain regions. If so, it becomes important to investigate if this relationship holds globally. But responses to a consistently-worded question over many regions have not been analyzed heretofore. Our study is also different in that we use the Cantril Self-Anchoring Striving Scale (Cantril 1965) to measure SWB, while previous related studies used life satisfaction (Chindarkar 2014; Otrachshenko and Popova 2014) and happiness (Bucchianeri 2007; Graham and Markowitz 2011). Kahneman and Deaton (2010) speculated that the Cantril question is "a purer measure of life evaluation than the life satisfaction, which has an emotional aspect." Migration, a big decision for an individual, is unlikely to reflect mainly emotional behavior, so we choose to focus on responses to the Cantril question. We also use a life satisfaction question to conduct a robustness checks. Furthermore, we compare the relative importance of SWB and income in explaining variations in migration desires, motivated by the fact that SWB may capture unobserved migration determinants which income does not capture.

\section{Data and methods}

The Gallup World Poll has been conducted annually in 161 countries since 2006. Most countries have about 1,000 respondents (older than 15) for each survey wave (mostly one wave per year). The latest Gallup World Poll dataset has been accumulated to over 1,000,000 observations and 2,000 survey questions, including individual characteristics, subjective well-being, migration questions, and many more. With the same questions 
asked in multiple countries, the Gallup World Poll provides an opportunity for a global scale study. However, it should be noted that some questions are only asked in certain countries during certain survey waves, so the number of questions eligible for a global study is much less than 2,000. Also, the data used in this study was collected from 2007 to 2012, since an international migration desire question was not asked in 2006. About 423,000 observations and 154 countries are involved in the estimation of our baseline model (Model 1 in Table 1). In our analysis, SWB is measured based on the Cantril Self-Anchoring Striving Scale (Cantril 1965). A life satisfaction question is then used as a robustness check. An international migration desire question is used for the main results, and a question related to migration intention is then used as a robustness check. The following are the main survey questions used in our analysis (other questions used for robustness checks will be listed when specific robustness check is discussed):

- The Cantril question: Please imagine a ladder with steps numbered from zero at the bottom to ten at the top. Suppose we say that the top of the ladder represents the best possible life for you, and the bottom of the ladder represents the worst possible life for you. On which step of the ladder would you say you personally feel you stand at this time, assuming that the higher the step the better you feel about your life, and the lower the step the worse you feel about it? Which step comes closest to the way you feel?

- The life satisfaction question: All things considered, how satisfied are you with your life as a whole these days? Use a 0 to 10 scale, where 0 is dissatisfied and 10 is satisfied.

- International migration desire question: Ideally, if you had the opportunity, would you like to move permanently to another country, or would you prefer to continue living in this country?

- Migration intention question (international and internal): In the next 12 months, are you likely or unlikely to move away from the city or area where you live?

First, based on the data from all the countries, we estimate the effects of SWB on international migration desires using a logistic regression model:

$$
\ln \left(\frac{P\left(I M_{i j t}\right)}{1-P\left(I M_{i j t}\right)}\right)=\beta_{0}+\beta_{1} S W B_{i j t}+\beta_{2} \text { Income }_{i j t}+\sum_{k=3}^{9} \beta_{k} I_{1 n d_{i j t}}+Z_{j}+W_{t}+\varepsilon_{i j t}
$$

where $P\left(I M_{i j t}\right)$ denotes the probability of having an international migration desire for respondent $\mathrm{i}$ in country $\mathrm{j}$ in survey wave $\mathrm{t} ; S W B_{i j t}$ denotes the individual SWB level and is treated as a categorical variable in the model; Income $_{i j t}$ denotes household income (in international dollars), which is included in the model since it may be correlated with both SWB and migration desire, thus would cause an omitted variable bias if it is not included; We also control for seven individual characteristics, denoted as Ind ${ }_{i j t}$, including access to social network, marital status, education level, gender, age, family size, and rural/urban residence; $Z_{j}$ is country fixed effects, controlling for country-level time-invariant factors which may affect individual migration desire; $W_{t}$ is survey wave fixed effects; and $\varepsilon_{i j t}$ is the error term. It should be noted that the Gallup World Poll 
Table 1 Logistic regression of international migration desire on SWB using individual level data

\begin{tabular}{|c|c|c|c|c|c|c|}
\hline \multirow[b]{3}{*}{ Variables } & \multicolumn{6}{|c|}{ International migration desire } \\
\hline & \multicolumn{3}{|c|}{$\begin{array}{l}\text { Model } 1 \text { (based on the } \\
\text { Cantril question) }\end{array}$} & \multicolumn{3}{|c|}{$\begin{array}{l}\text { Model } 2 \text { (based on the life } \\
\text { satisfaction question) }\end{array}$} \\
\hline & Coefficient & Robust SE & Pred. Prob. & Coefficient & Robust SE & Pred. Prob. \\
\hline \multicolumn{7}{|l|}{ Subjective well-being } \\
\hline 0 & & & $25.4 \%$ & & & $30.3 \%$ \\
\hline 1 & $-0.106^{*}$ & 0.058 & $23.5 \%$ & -0.006 & 0.191 & $30.1 \%$ \\
\hline 2 & $-0.250^{* * *}$ & 0.053 & $21.0 \%$ & $-0.335^{*}$ & 0.185 & $23.7 \%$ \\
\hline 3 & $-0.321^{* * *}$ & 0.050 & $19.8 \%$ & $-0.316^{* *}$ & 0.154 & $24.0 \%$ \\
\hline 4 & $-0.424^{* * *}$ & 0.049 & $18.3 \%$ & $-0.450^{* * *}$ & 0.111 & $21.7 \%$ \\
\hline 5 & $-0.542^{* * *}$ & 0.051 & $16.6 \%$ & $-0.644^{* * *}$ & 0.134 & $18.6 \%$ \\
\hline 6 & $-0.653^{* * *}$ & 0.055 & $15.1 \%$ & $-0.838^{* * *}$ & 0.144 & $15.8 \%$ \\
\hline 7 & $-0.696^{* * *}$ & 0.056 & $14.5 \%$ & $-0.923^{* * *}$ & 0.136 & $14.7 \%$ \\
\hline 8 & $-0.839^{* * *}$ & 0.061 & $12.8 \%$ & $-1.009^{* * *}$ & 0.132 & $13.7 \%$ \\
\hline 9 & $-0.896^{* * *}$ & 0.069 & $12.2 \%$ & $-1.264^{* * *}$ & 0.157 & $10.9 \%$ \\
\hline 10 & $-0.756^{* * *}$ & 0.067 & $13.8 \%$ & $-1.119^{* * *}$ & 0.148 & $12.4 \%$ \\
\hline Log (Household Income) & -0.009 & 0.009 & & -0.006 & 0.019 & \\
\hline \multicolumn{7}{|l|}{ Relatives or Friends Abroad } \\
\hline No & & & $13.8 \%$ & & & $14.3 \%$ \\
\hline Yes & $0.689^{* * *}$ & 0.026 & $24.1 \%$ & $0.528^{* * *}$ & 0.055 & $22.0 \%$ \\
\hline \multicolumn{7}{|l|}{ Marital Status } \\
\hline Single/Never married & & & $20.2 \%$ & & & $21.0 \%$ \\
\hline Married & $-0.393^{* * *}$ & 0.025 & $14.6 \%$ & $-0.501^{* * *}$ & 0.070 & $13.9 \%$ \\
\hline Separated & $-0.097^{* *}$ & 0.041 & $18.7 \%$ & -0.083 & 0.126 & $19.7 \%$ \\
\hline Divorced & -0.022 & 0.034 & $19.9 \%$ & 0.019 & 0.112 & $20.7 \%$ \\
\hline Widowed & $-0.543^{* * *}$ & 0.044 & $12.9 \%$ & $-0.429 * * *$ & 0.119 & $14.8 \%$ \\
\hline Domestic partner & $-0.181^{* * *}$ & 0.031 & $17.5 \%$ & $-0.219^{* * *}$ & 0.078 & $17.6 \%$ \\
\hline Education up to 8 years & & & $14.8 \%$ & & & $14.4 \%$ \\
\hline 9-15 years of education & $0.208^{* * *}$ & 0.023 & $17.6 \%$ & $0.206^{* * *}$ & 0.063 & $17.1 \%$ \\
\hline a 4-year college degree & $0.257^{* * *}$ & 0.040 & $18.3 \%$ & $0.249^{* * *}$ & 0.086 & $17.7 \%$ \\
\hline \multicolumn{7}{|l|}{ Gender } \\
\hline Male & & & $18.2 \%$ & & & $17.1 \%$ \\
\hline Female & $-0.245^{* * *}$ & 0.028 & $14.8 \%$ & $-0.131^{* * *}$ & 0.031 & $15.3 \%$ \\
\hline \multicolumn{7}{|l|}{ Age } \\
\hline$<20$ & & & $24.2 \%$ & & & $24.8 \%$ \\
\hline $21 \sim 30$ & $-0.089^{* * *}$ & 0.022 & $22.6 \%$ & -0.114 & 0.062 & $22.8 \%$ \\
\hline $31 \sim 40$ & $-0.309^{* * *}$ & 0.030 & $19.0 \%$ & $-0.325^{* * *}$ & 0.079 & $19.3 \%$ \\
\hline $41 \sim 50$ & $-0.587^{* * *}$ & 0.040 & $15.1 \%$ & $-0.551^{* * *}$ & 0.093 & $16.0 \%$ \\
\hline $51 \sim 60$ & $-0.915^{* * *}$ & 0.046 & $11.3 \%$ & $-0.790^{* * *}$ & 0.114 & $13.0 \%$ \\
\hline $61 \sim 70$ & $-1.439^{* * *}$ & 0.060 & $7.0 \%$ & $-1.304^{* * *}$ & 0.125 & $8.2 \%$ \\
\hline $71 \sim 80$ & $-1.904^{* * *}$ & 0.082 & $4.5 \%$ & $-1.847^{* * *}$ & 0.166 & $5.0 \%$ \\
\hline$>80$ & $-1.484^{* * *}$ & 0.229 & $6.7 \%$ & $-1.742^{* * *}$ & 0.302 & $5.5 \%$ \\
\hline Family Size & $0.011^{* * *}$ & 0.003 & & 0.009 & 0.010 & \\
\hline 1 & & & $15.8 \%$ & & & $15.7 \%$ \\
\hline 2 & & & $15.9 \%$ & & & $15.9 \%$ \\
\hline
\end{tabular}




\begin{tabular}{|c|c|c|c|c|c|c|}
\hline 3 & & & $16.1 \%$ & & & $16.0 \%$ \\
\hline 4 & & & $16.2 \%$ & & & $16.1 \%$ \\
\hline 5 & & & $16.4 \%$ & & & $16.3 \%$ \\
\hline 6 & & & $16.5 \%$ & & & $16.4 \%$ \\
\hline 7 & & & $16.7 \%$ & & & $16.5 \%$ \\
\hline 8 & & & $16.8 \%$ & & & $16.6 \%$ \\
\hline 9 & & & $17.0 \%$ & & & $16.8 \%$ \\
\hline 10 & & & $17.1 \%$ & & & $16.9 \%$ \\
\hline \multicolumn{7}{|l|}{ Respondent lives in } \\
\hline A rural area or on a farm & & & $14.1 \%$ & & & $14.1 \%$ \\
\hline a small town or village & $0.153^{* * *}$ & 0.023 & $16.0 \%$ & $0.118^{* *}$ & 0.057 & $15.6 \%$ \\
\hline a large city & $0.329^{* * *}$ & 0.030 & $18.6 \%$ & $0.335^{* * *}$ & 0.066 & $18.6 \%$ \\
\hline the suburb of a large city & $0.313^{* * *}$ & 0.035 & $18.3 \%$ & $0.248^{* * *}$ & 0.085 & $17.4 \%$ \\
\hline Constant & -0.130 & 0.170 & & -1.380 & 0.239 & \\
\hline Country dummies & & Yes & & & Yes & \\
\hline Survey wave dummies & & Yes & & & Yes & \\
\hline Number of Observations & & 423132 & & & 44714 & \\
\hline Pseudo $R^{2}$ & & 0.1427 & & & 0.1455 & \\
\hline
\end{tabular}

Note: International migration desire is the binary dependent variable. SWB in Model 1 is represented by the responses to the Cantril question, and SWB in Model 2 is represented by the responses to the life satisfaction question. SWB is treated as a categorical variable. SWB $=0$ ("worst possible life" or "dissatisfied") is used as the reference group. The independent variables without a coefficient mean that they are used as references (such as male). Robust standard errors are corrected for clustering at the country level. ${ }^{*} p<0.1 ;{ }^{* *} p<0.05 ;{ }^{* * *} p<0.01$.

does not conduct follow-up interviews, so a panel data model is not suitable for an individual level analysis. We use survey weights provided by the Gallup World Poll to ensure a nationally representative estimation. Responses to the survey questions within the same country may be correlated due to some common characteristics, so robust standard errors are corrected for clustering at the country level. We would prefer to use the SWB differences before and after migration, in order to compare it with the income differences, since the latter is a major determinant of international migration. However, this variable is unavailable to us.

In addition to the individual-level analysis, we also conduct a cross-country analysis. Equation (2) is used to study the relationship between national average migration desire, national average SWB, and GDP per capita. It should be noted that in Equation (2), national average SWB and migration desire are the average from all respondents for the period of 2007-2012. Since data quality and the collecting process vary across countries (which may generate outlier countries), robust regression is used.

$$
I M_{j}=\delta_{0}+\delta_{1} S W B_{j}+\delta_{2} \text { GDPperCapita } j+v_{j}
$$

\section{Results and discussion}

By estimating the logistic regression in Equation (1), we found that higher SWB levels are associated with a trend toward lower predicted probabilities for international migration desires, after controlling for income and several individual characteristics (Figure 1 


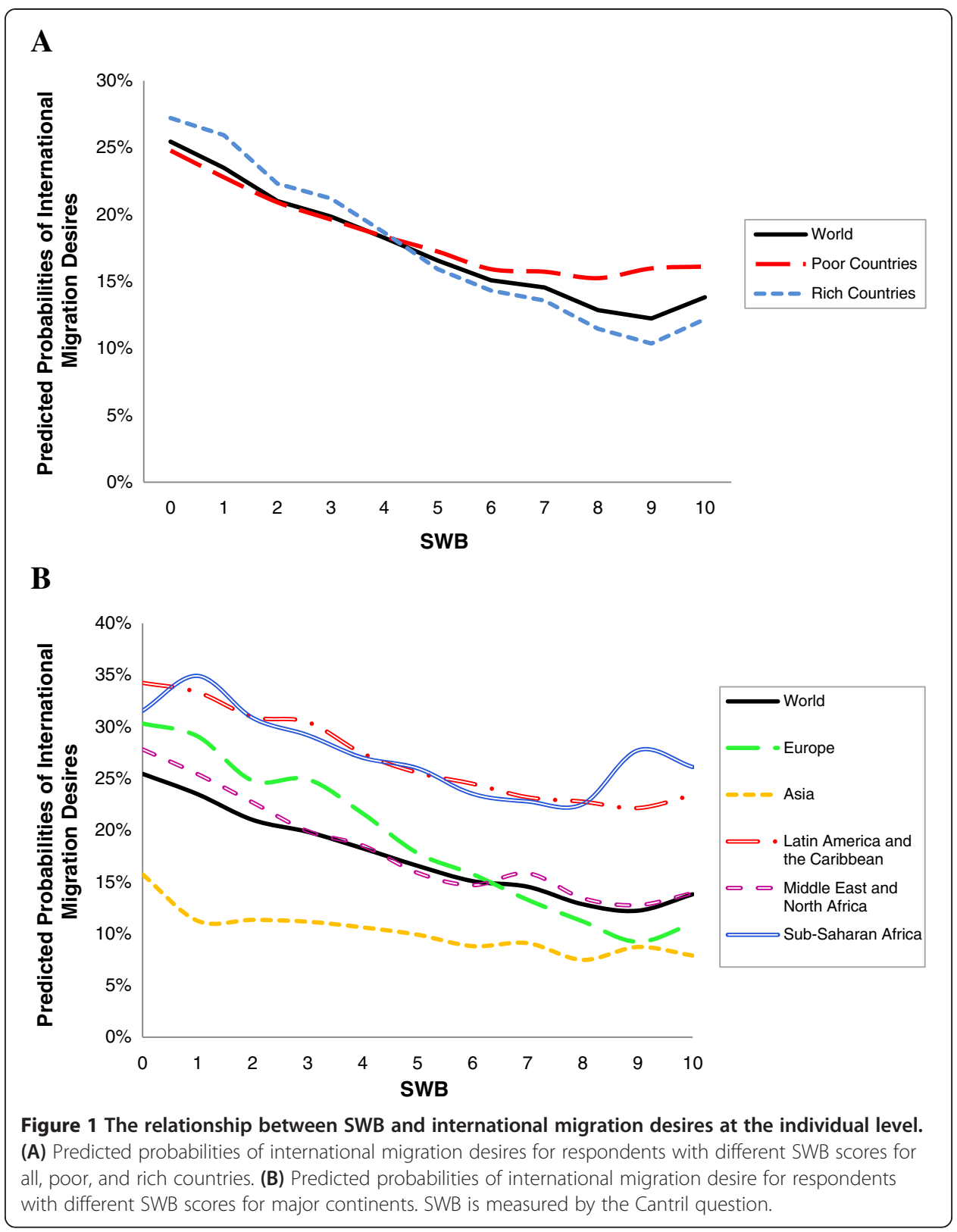

and Model 1 in Table 1). Individuals at the high end of the SWB scale have a lower probability of desire to permanently move to another country than individuals at the low end of the SWB scale, ranging from a probability of $25.4 \%$ for a respondent with the lowest SWB level to a probability of $13.8 \%$ for a respondent with the highest SWB level based on the Cantril question. Our finding about the relationship between migration desire and SWB is robust to an alternative SWB question. In Model 2 in Table 1, when SWB is represented by the life satisfaction question, we predict migration probabilities similar to the model using the Cantril question, indicating that these two questions are competitive measures of SWB. Our main result about the SWB-migration link is also robust to alternative migration questions (see Appendix A for more details). We observed that the lowest probability of $12.2 \%$ is associated with respondents with the second best well-being level when the Cantril question is used (Model 1 in Table 1). 
This phenomenon is also observed when a life satisfaction question is used to represent SWB, for which the lowest probability of $10.9 \%$ is associated with respondent with the second best SWB level (Model 2 in Table 1). However, investigating why the respondents with the "best" self-perceived life have a different behavior as compared to other respondents is beyond the scope of this study.

As shown in Table 1, we found that the coefficient estimates of control variables such as household income, access to social networks, marital status, education, gender, age, family size, and rural/urban residence are generally significant and have the expected signs. Respondents who have relatives or friends in another country whom they can count on for help have a predicted probability of $24.1 \%$ for international migration desire, as compared to $13.8 \%$ for respondents who do not have someone abroad whom they can count on. This result demonstrates the importance of network in individual international migration desire, which is in line with previous migration studies (Pedersen et al. 2008). An individual with relatives or friends in another country tend to have more information about international migration, and is more likely to obtain a job in another country, and thus is more likely to have migration desire. Respondents currently in a marriage, relationship, or widowed have less international migration desire compared to respondents who are single, separated, or divorced. Respondents with higher education level are more likely to have international migration desire. In specific, respondents with completed elementary education or less (up to 8 years of basic education) have a predicted probability of international migration desire of $14.8 \%$. This probability is $17.6 \%$ for respondents with secondary education and some education beyond secondary education (9-15 years of education), and 18.3\% for respondents who have completed four years of education beyond high school and/or received a four-year college degree. A possible explanation for this result is that higher educated respondents may have more knowledge about the other countries and have more confidence in finding a job in foreign countries. Male respondents are on average 3.4\% more likely to have a desire to move permanently to another country compared to female respondents. The predicted probabilities indicate that younger respondents are more likely to have higher international migration desire. Members of larger families have a higher probability of international migration desire. Whether a respondent lives in urban, suburban, or rural areas also affects international migration desire. Respondents living in a rural area or on a farm have the lowest probabilities of international migration desire (14.1\%), and respondents from a small town or village tend to have higher probabilities (16.0\%). Respondents living in a large city or the suburb of a large city have the highest probabilities of international migration desire, $18.6 \%$ and $18.3 \%$, respectively.

A key concern is whether international migration desire is related to the actual migration. Van Dalen and Henkens (2008 and 2013) and Creighton (2013) showed that migration intentions and aspirations are good predictors of future actual migration behavior. Here we address this concern using the survey question "Have you done any preparation for this move? For example, have you applied for residency or a visa, purchased the ticket, etc.?" which would be asked if the respondents answer yes to the migration desire question. We observed that $39 \%$ of the respondents with international migration desire said they were preparing for the move. In Figure 2A, among those respondents who have migration desire, higher SWB is associated with slightly higher likelihood of preparing for migration. Thus Figure $2 \mathrm{~B}$ shows that the relationship 
between SWB and the likelihood of preparing for migration based on the whole population is slightly weaker as compared to the case when international migration desire was used as in Figure 1. However, in Figure 2B, we still observed a clear downward trend - respondents with higher SWB are less likely to prepare for migration, which provides another robustness check for our main finding in addition to the alternative migration questions in Appendix A. There is also a concern that we found a relationship between migration desire and SWB simply because strong migration desire itself may reduce SWB. We address the concern by showing that preparing for migration based on the whole sample is also negatively associated with SWB, since it is less likely that preparing for migration will negatively influence SWB.

Next, we compare the performance of SWB and income in explaining migration desire. We use the whole sample including all the countries (Models 1-3 in Table 2), and we also use the part of the sample with poor countries (Models 4-6 in Table 2) or rich

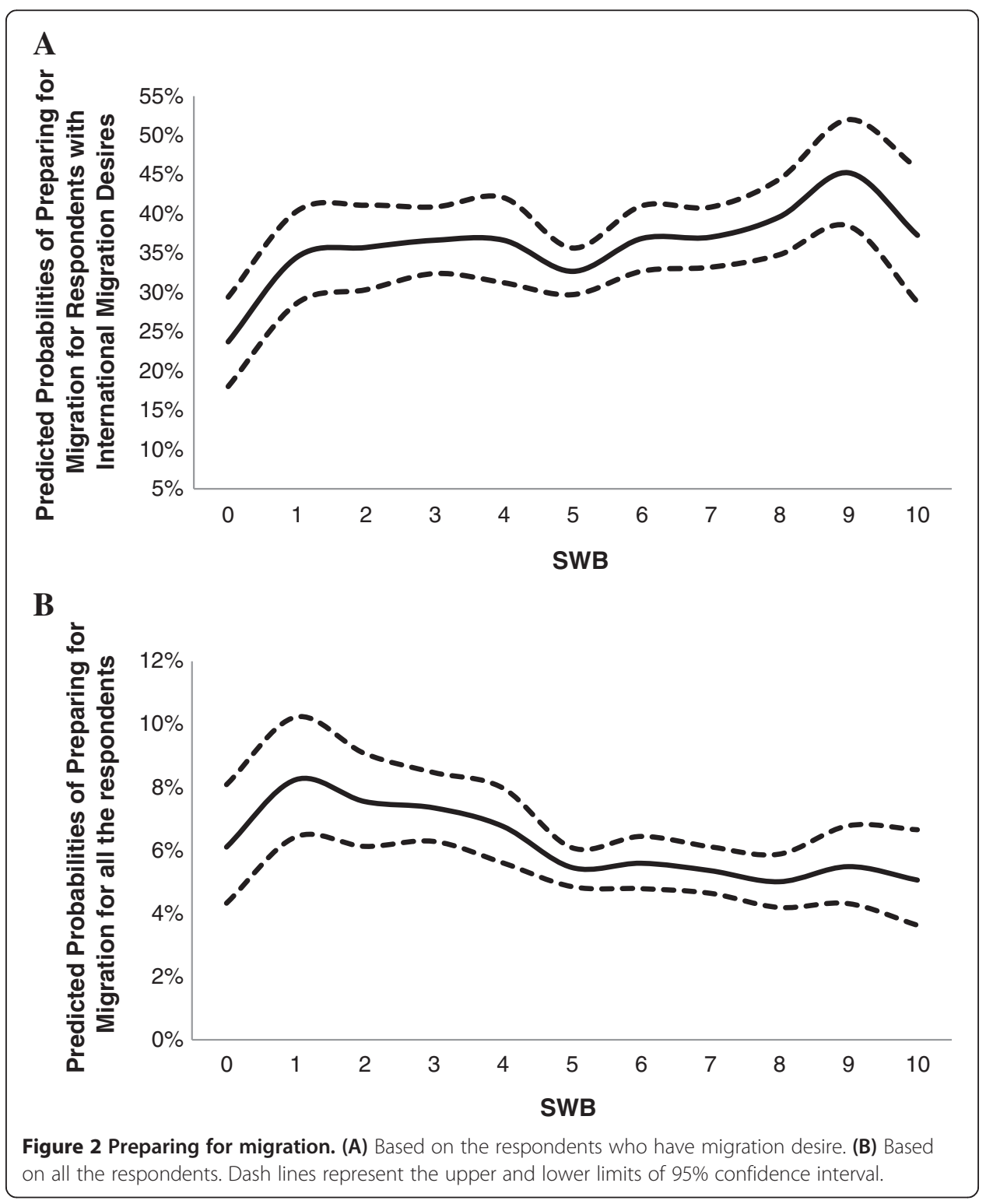


countries only (Models 7-9 in Table 2). As shown in Table 2, the negative relationship between SWB and international migration desires is robust to whether or not we control for household income, while the significance of the household income coefficient varies across the samples and models. Thus, compared to household income, SWB may be a more robust indicator of international migration desires. To further test this result, we compared SWB and income in terms of the increment in $\mathrm{R}^{2}$, which would show a variable's contribution to the goodness of fit of the regression model. In Table 2, removing the income variable from the full model (Equation 1) does not affect pseudo $R^{2}$ for any samples, while removing SWB variable from the full model reduces pseudo $R^{2}$ in all cases, showing that SWB contributes more to the goodness of fit of the model than income. The result of the increment in $R^{2}$ value still holds when SWB is treated as a continuous variable (Table 3). But household income may be a poor measure for the individual; thus its explanatory power is presumably lower than SWB, which is an individual measure. To address this concern, we constructed a new variable - household income divided by the family size, and we found that the results in both Table 2 and the increment in $R^{2}$ all hold (results not shown due to space limitations). This additional increment in pseudo $\mathrm{R}^{2}$ from SWB may be due to the fact that SWB captures both the income factor and other unobserved factors for which income does not capture (Freeman 1978). Those non-pecuniary determinants of SWB, e.g., health, separation, and social contact (Freeman 1978; Dolan et al. 2008), are likely to result in SWB better explaining the variations in international migration than using income alone. Our result is also in line with Mansoor and Qullin (2006) who argued that overall quality of life, in additional to income difference, may drive migration. It should be noted that, although SWB appears be more powerful than income in explaining migration desire variations in our study, we do not imply a diminished importance of income as a causal factor. Using the Gallup data, Stevenson and Wolfers (2013) found that SWB is positively associated with income. Thus the negative correlation between SWB and migration desire may arise in part indirectly from income. Since we are interested in a correlation instead of the causal relationship between SWB and migration, endogeneity of this sort is not a concern here.

It is likely that there are different response styles to the same survey question in different regions, thus generating a different SWB-migration link. Is our main result driven by respondents from specific regions? To answer this question, we first estimate this relationship between SWB and migration desire separately for major continents using Equation (1). In Figure 1B, respondents from Latin America and Sub-Saharan Africa have higher international migration desires than other regions. The possible reasons could be colonial ties, shared language, and geographic proximity to migrant destination countries in Europe and North America. On the other hand, language barriers and geographic distances to migrant destination countries may explain low international migration desires in Asia. Although respondents from different regions may report different levels of migration desire and SWB, we still observed a similar downward trend in their international migration desires as SWB level goes up (Figure 1B). Then also using Equation (1), we further estimated the relationship between SWB and migration desire separately for each country. To better compare this relationship among countries, SWB is now treated as a continuous variable in Equation (1) so that we can generate a linear relationship for each country. We found that the relationship 
Table 2 Logistic regression of international migration desire on SWB using individual level data

\begin{tabular}{|c|c|c|c|c|c|c|c|c|c|c|}
\hline \multirow[b]{2}{*}{ Variables } & \multicolumn{2}{|c|}{ Model (1) } & \multicolumn{2}{|c|}{ Model (2) } & \multirow{2}{*}{$\begin{array}{l}\text { Model (3) } \\
\text { Coefficient }\end{array}$} & \multirow{2}{*}{$\begin{array}{l}\text { Model (4) } \\
\text { Poor } \\
\text { Coefficient }\end{array}$} & \multirow{2}{*}{$\begin{array}{l}\text { Model (5) } \\
\text { Poor } \\
\text { Coefficient }\end{array}$} & \multirow{2}{*}{$\begin{array}{l}\text { Model (6) } \\
\text { Poor } \\
\text { Coefficient }\end{array}$} & \multirow{2}{*}{$\begin{array}{l}\text { Model (7) } \\
\text { Rich } \\
\text { Coefficient }\end{array}$} & \multirow{2}{*}{$\begin{array}{l}\text { Model (8) } \\
\text { Rich } \\
\text { Coefficient }\end{array}$} \\
\hline & Coefficient & Probability & Coefficient & Probability & & & & & & \\
\hline \multicolumn{11}{|c|}{ Subjective well-being } \\
\hline 0 & & $25.4 \%$ & & $25.5 \%$ & & & & & & \\
\hline \multirow[t]{2}{*}{1} & $-0.106^{*}$ & $23.5 \%$ & $-0.107^{*}$ & $23.6 \%$ & & -0.111 & -0.111 & & -0.065 & -0.068 \\
\hline & $(0.058)$ & & $(0.058)$ & & & $(0.077)$ & $(0.077)$ & & $(0.078)$ & $(0.077)$ \\
\hline \multirow[t]{2}{*}{2} & $-0.250^{* * *}$ & $21.0 \%$ & $-0.251^{* * *}$ & $21.1 \%$ & & $-0.220^{* * *}$ & $-0.219^{* * *}$ & & $-0.264^{* * *}$ & $-0.269^{* * *}$ \\
\hline & $(0.053)$ & & $(0.053)$ & & & $(0.066)$ & $(0.066)$ & & $(0.083)$ & $(0.083)$ \\
\hline \multirow[t]{2}{*}{3} & $-0.321^{* * *}$ & $19.8 \%$ & $-0.323^{* * *}$ & $19.9 \%$ & & $-0.299^{* * *}$ & $-0.298^{* * *}$ & & $-0.328^{* * *}$ & $-0.336^{* * *}$ \\
\hline & $(0.050)$ & & $(0.050)$ & & & $(0.064)$ & $(0.064)$ & & $(0.075)$ & $(0.075)$ \\
\hline \multirow[t]{2}{*}{4} & $-0.424^{* * *}$ & $18.3 \%$ & $-0.428^{* * *}$ & $18.3 \%$ & & $-0.382^{* * *}$ & $-0.380^{* * *}$ & & $-0.489^{* * *}$ & $-0.499^{* * *}$ \\
\hline & $(0.049)$ & & $(0.049)$ & & & $(0.061)$ & $(0.061)$ & & $(0.078)$ & $(0.079)$ \\
\hline \multirow[t]{2}{*}{5} & $-0.542^{* * *}$ & $16.6 \%$ & $-0.547^{* * *}$ & $16.6 \%$ & & $-0.459^{* * *}$ & $-0.456^{* * *}$ & & $-0.680^{* * *}$ & $-0.692^{* * *}$ \\
\hline & $(0.051)$ & & $(0.051)$ & & & $(0.067)$ & $(0.066)$ & & $(0.074)$ & $(0.075)$ \\
\hline \multirow[t]{2}{*}{6} & $-0.653^{* * *}$ & $15.1 \%$ & $-0.658^{* * *}$ & $15.1 \%$ & & $-0.554^{* * *}$ & $-0.551^{* * *}$ & & $-0.806^{* * *}$ & $-0.821^{* * *}$ \\
\hline & $(0.055)$ & & $(0.056)$ & & & $(0.070)$ & $(0.069)$ & & $(0.081)$ & $(0.082)$ \\
\hline \multirow[t]{2}{*}{7} & $-0.696^{* * *}$ & $14.5 \%$ & $-0.702^{* * *}$ & $14.5 \%$ & & $-0.569^{* * *}$ & $-0.565^{* * *}$ & & $-0.867^{* * *}$ & $-0.884^{* * *}$ \\
\hline & $(0.056)$ & & $(0.057)$ & & & $(0.075)$ & $(0.075)$ & & $(0.078)$ & $(0.079)$ \\
\hline \multirow[t]{2}{*}{8} & $-0.839^{* * *}$ & $12.8 \%$ & $-0.846^{* * *}$ & $12.8 \%$ & & $-0.605^{* * *}$ & $-0.602^{* * *}$ & & $-1.060^{* * *}$ & $-1.078^{* * *}$ \\
\hline & $(0.061)$ & & $(0.061)$ & & & $(0.075)$ & $(0.075)$ & & $(0.083)$ & $(0.084)$ \\
\hline \multirow[t]{2}{*}{9} & $-0.896^{* * *}$ & $12.2 \%$ & $-0.903^{* * *}$ & $12.2 \%$ & & $-0.550^{* * *}$ & $-0.547^{* * *}$ & & $-1.173^{* * *}$ & $-1.192^{* * *}$ \\
\hline & $(0.069)$ & & $(0.070)$ & & & $(0.087)$ & $(0.088)$ & & $(0.092)$ & $(0.093)$ \\
\hline \multirow[t]{2}{*}{10} & $-0.756^{* * *}$ & $13.8 \%$ & $-0.761^{* * *}$ & $13.8 \%$ & & $-0.540^{* * *}$ & $-0.537^{* * *}$ & & $0.991^{* * *}$ & $-1.007^{* * *}$ \\
\hline & $(0.067)$ & & $(0.067)$ & & & $(0.085)$ & $(0.083)$ & & $(0.090)$ & $(0.090)$ \\
\hline
\end{tabular}


Table 2 Logistic regression of international migration desire on SWB using individual level data (Continued)

\begin{tabular}{|c|c|c|c|c|c|c|c|c|c|}
\hline Log (Household Income) & -0.009 & & $-0.041^{* * *}$ & 0.005 & & -0.018 & $-0.021^{*}$ & & $-0.067^{* * *}$ \\
\hline & (0.009) & & $(0.009)$ & $(0.013)$ & & $(0.014)$ & $(0.012)$ & & $(0.011)$ \\
\hline Individual characteristics & Yes & Yes & Yes & Yes & Yes & Yes & Yes & Yes & Yes \\
\hline Country dummies & Yes & Yes & Yes & Yes & Yes & Yes & Yes & Yes & Yes \\
\hline Survey wave dummies & Yes & Yes & Yes & Yes & Yes & Yes & Yes & Yes & Yes \\
\hline Observations & 423132 & 423132 & 423132 & 212608 & 212608 & 212608 & 210524 & 210524 & 210524 \\
\hline Pseudo $R^{2}$ & 0.1427 & 0.1427 & 0.1385 & 0.1584 & 0.1584 & 0.1560 & 0.1225 & 0.1225 & 0.1148 \\
\hline
\end{tabular}

Note: International migration desire is a binary dependent variable. SWB is represented by the responses to the Cantril question. SWB is treated as a categorical variable. SWB $=0$ is used as the reference group. Robust standard errors are corrected for clustering at the country level. ${ }^{*} \mathrm{p}<0.1 ;{ }^{* *} \mathrm{p}<0.05 ; * * * \mathrm{p}<0.01$ 
is negative and significant in $83.1 \%$ of rich countries and $55.1 \%$ of poor countries at the $5 \%$ significance level. If we lower the threshold and do not require significance, $95.8 \%$ of rich countries and $87.0 \%$ of poor countries have negative relationship between migration desire and SWB (Figure 3A). This shows that the negative relationship between SWB and migration desire holds in most countries.

Next, we conducted a cross-country analysis, which only explores between-country variation but not within-country variation. We use the average GDP per capita for the period 2007-2012 to proxy for the national average income. In Figure 3A, we observed that, among rich countries, those at the higher end of the GDP per capita scale tend to have a stronger relationship between migration desire and SWB than those at the lower end, while such a trend was not observed among poor countries. This indicates that SWB may statistically perform better among rich countries when explaining the desire to migrate at the country level. To gain further insight, we regressed the national average migration desire on the national average SWB and GDP per capita as Equation (2). Among poor countries, the desire to migrate is negatively associated with GDP per capita, while the relationship between SWB and the desire to migrate is not significant (Figure 3B and Table 4). Among rich countries, SWB outperforms GDP per capita countries with higher SWB have lower national average migration desire, while the coefficient for GDP per capita is not significant (Figure 3C and Table 4). A possible explanation is that rich countries have mostly fulfilled people's basic needs, therefore, compared to using income alone, SWB which may cover both income and other factors could have a relatively larger effects on migration desires, as "quality of life, rather than income alone, is often seen as the key concern in affluent societies" (Delhey and Kroll 2012). On the other hand, "economic indicators were extremely important in the early stages of economic development, when the fulfillment of basic needs was the main issue" (Diener and Seligman 2004), which may address why GDP per capita better explains different migration desires among poor countries. This cross-sectional, crosscountry regression should be interpreted with caution, since both national average migration desire and SWB may be correlated with time-invariant confounding factors such as cultural or political characteristics. Of course, a cross-country panel data analysis would be possible here. However, this would be an unbalanced panel data. Furthermore, with a relatively short panel with only six years, we prefer to use the crosssectional (between-country) variations, instead of time-series (within-country) variations for the linkage between average migration and average migration desire. Therefore, we conducted a cross-sectional regression here.

Going back to the individual data, when splitting the individual data by rich and poor countries, we also found that individual desire to emigrate is more sensitive to SWB in rich countries than in poor countries (Figure 1A and Models 4-9 in Table 2). This is consistent with the earlier result when estimating Equation (1) separately for each country in Figure 3A, that SWB is not significantly associated with migration desire in some poor countries - although $87.0 \%$ of poor countries have negative relationship between migration desire and SWB, only $55.1 \%$ of poor countries have a significant and negative relationship (at the 5\% significance level). Interestingly, another result from the cross-country analysis - poor countries have a stronger effect of GDP per capita on national average desire to emigrate - could not be replicated when individual data is analyzed. Instead, we found that household income has a less significant relationship 
Table 3 Logistic regression of international migration desire on SWB (continuous variable) using individual level data

\begin{tabular}{|c|c|c|c|c|c|c|c|c|c|}
\hline Variables & Coefficient & Coefficient & Coefficient & $\begin{array}{l}\text { Model (4) } \\
\text { Poor } \\
\text { Coefficient }\end{array}$ & $\begin{array}{l}\text { Model (5) } \\
\text { Poor } \\
\text { Coefficient }\end{array}$ & $\begin{array}{l}\text { Model (6) } \\
\text { Poor } \\
\text { Coefficient }\end{array}$ & $\begin{array}{l}\text { Model (7) } \\
\text { Rich } \\
\text { Coefficient }\end{array}$ & $\begin{array}{l}\text { Model (8) } \\
\text { Rich } \\
\text { Coefficient }\end{array}$ & $\begin{array}{l}\text { Model (9) } \\
\text { Rich } \\
\text { Coefficient }\end{array}$ \\
\hline \multirow[t]{2}{*}{ SWB (continuous) } & $-0.090^{* * *}$ & $-0.091^{* * *}$ & & $-0.064^{* * *}$ & $-0.063^{* * *}$ & & $-0.121^{* * *}$ & $-0.124^{* * *}$ & \\
\hline & $(0.006)$ & $(0.006)$ & & $(0.006)$ & $(0.006)$ & & $(0.008)$ & $(0.008)$ & \\
\hline \multirow[t]{2}{*}{ Log (Household Income) } & -0.011 & & $-0.041^{* * *}$ & 0.002 & & -0.018 & $-0.025^{* *}$ & & $-0.067^{* * *}$ \\
\hline & $(0.009)$ & & $(0.009)$ & $(0.014)$ & & $(0.014)$ & $(0.012)$ & & $(0.011)$ \\
\hline Individual characteristics & Yes & Yes & Yes & Yes & Yes & Yes & Yes & Yes & Yes \\
\hline Country dummies & Yes & Yes & Yes & Yes & Yes & Yes & Yes & Yes & Yes \\
\hline Survey wave dummies & Yes & Yes & Yes & Yes & Yes & Yes & Yes & Yes & Yes \\
\hline Observations & 423132 & 423132 & 423132 & 212608 & 212608 & 212608 & 210524 & 210524 & 210524 \\
\hline Pseudo $R^{2}$ & 0.1424 & 0.1424 & 0.1385 & 0.1581 & 0.1581 & 0.1560 & 0.1219 & 0.1218 & 0.1148 \\
\hline
\end{tabular}

Note: International migration desire is a binary dependent variable. SWB is represented by the responses to the Cantril question. SWB is treated as a continuous variable. Robust standard errors are corrected for clustering at the country level. ${ }^{*} p<0.1 ;{ }^{* *} p<0.05 ;{ }^{* * *} p<0.01$ 
with the desire to emigrate in poor countries than in rich countries (Table 2). One explanation might be that some rich people in poor countries, unsatisfied that they are staying in a poor society, desire to emigrate as much as poor people. On the other hand, poor people in poor countries might be trapped in places where they have insufficient resources to move (Foresight 2011), which may even diminish their migration desires. Besides, a survey conducted in poor countries might yield less accurate income data. These factors may weaken the effect of household income on the desire to emigrate in poor countries. When the country-level data are used, since there is no within-country variation, we are able to identify a strong effect of income on the national migration desire for poor countries.

There are some limitations in our approach. We excluded the respondents who refused to answer the question or don't know the answer. It is possible that these respondents have different distributions of characteristics compared to others, which may cause bias. SWB may be affected by events happening before the interview (Krueger and Schkade 2008). Alternative measurements of SWB, such as time use, have been proposed (Krueger et al. 2009). Furthermore, there may be certain subjective

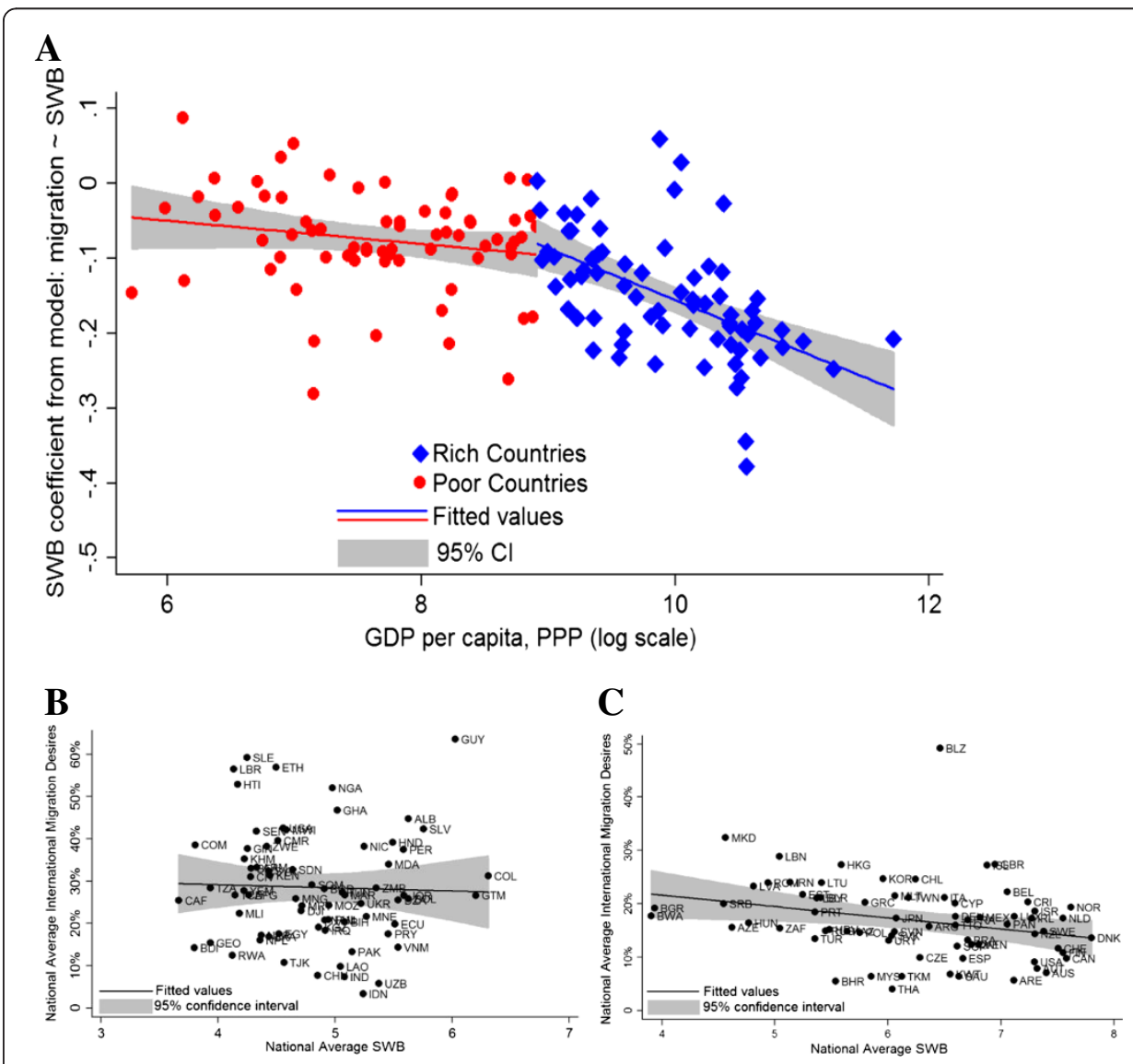

Figure 3 The relationship between SWB and international migration desires at the national level.

(A) Scatter plot of SWB coefficients representing the relationship between the desire to emigrate and SWB by country against natural logarithm of GDP per capita, PPP. Red dots represent 71 poor countries and blue dots represent 71 rich countries, which were divided by the median of GDP per capita. (B) Scatter plot of national average international migration desires against national average SWB in poor countries. (C) Scatter plot of national average international migration desires against national average SWB in rich countries. Gray area represents the $95 \%$ confidence interval. 
differences in interpreting SWB and migration across different countries. Since these limitations have either unbiased or small effects (see Appendix B for more details), the main conclusion of this paper - the negative relationship between SWB and migration desire - is not expected to be affected much by them.

\section{Conclusions}

Based on survey data covering 154 countries during the period of 2007-2012, we provided empirical evidence that international migration desire is negatively associated with SWB. This finding is robust to alternative survey questions such as migration intention and life satisfaction. It is also robust to whether or not controlling for an important migration determinant - income.

We further compare the relative importance of income and SWB in explaining the variations in international migration desire. Other studies have suggested that SWB may outperform objective economic measures in terms of measuring social welfare (Diener and Seligman 2004). Although there is some evidence, for instance, that the litthe improvement of GDP per capita in Africa fails to capture the huge improvement of health and education (Kenny 2011), empirical evidence for a direct comparison between subjective and objective measures in terms of their effects on essential social outcomes such as migration is still limited. Based on this study, compared to objective measures such as income which are well-established in the literature, SWB appears to better explain the variations in international migration desires, as $R^{2}$ increment from the SWB variable is larger than that from income. However, the better performance of SWB may arise because it captures both income and other components of the quality of life which influence migration. However, this result should be viewed with caution it is only based on a few survey questions from the Gallup World Poll; thus how well each survey question can represent certain indicator is different. For example, it is possible that the Cantril question is a good approximation of SWB, while the household income in international dollars (or even the household income divided by the family size) may not be a good approximation of individual purchasing power. In that case, we

Table 4 Cross-country regressions of average international migration desires on average SWB and GDP per capita

\begin{tabular}{|c|c|c|c|c|c|c|}
\hline \multirow{3}{*}{ Variables } & \multicolumn{6}{|c|}{ National Average International Migration Desires } \\
\hline & \multicolumn{3}{|c|}{ Poor countries } & \multicolumn{3}{|c|}{ Rich countries } \\
\hline & (1) & $(2)$ & (3) & (4) & (5) & (6) \\
\hline \multirow[t]{2}{*}{ Subjective Well-Being } & 0.035 & -0.009 & & $-0.025^{* *}$ & $-0.022^{* * *}$ & \\
\hline & $(0.036)$ & $(0.027)$ & & $(0.010)$ & $(0.008)$ & \\
\hline \multirow[t]{2}{*}{$\log ($ GDP per capita) } & $-0.051^{* *}$ & & $-0.036^{*}$ & 0.007 & & -0.018 \\
\hline & $(0.025)$ & & $(0.019)$ & $(0.015)$ & & $(0.012)$ \\
\hline \multirow[t]{2}{*}{ Constant } & $0.498^{* * *}$ & $0.323^{* *}$ & $0.556^{* * *}$ & $0.123^{* *}$ & $0.301^{* * *}$ & $0.341^{* * *}$ \\
\hline & $(0.155)$ & $(0.131)$ & $(0.146)$ & $(0.251)$ & $(0.049)$ & $(0.122)$ \\
\hline Number of countries & 71 & 71 & 71 & 71 & 71 & 71 \\
\hline
\end{tabular}

Note: The dependent variable is the national average international migration desires. Columns (1-3) represent poor countries, and columns (4-6) represent rich countries, which are determined by median GDP per capita. Standard errors are in parenthesis. ${ }^{*} \mathrm{p}<0.1 ;{ }^{* *} \mathrm{p}<0.05 ;{ }^{* * *} \mathrm{p}<0.01$. 
may underestimate the contribution of income to the goodness of fit of the model. Future research works should test our result with different approaches and data sets. When country-average data were used, SWB is a better indicator of international migration desires only among rich countries, while income performs better for poor countries. Our results do not diminish the importance of income in terms of explaining international migration - income may be the most important individual component of SWB.

While "domestic policy currently focuses heavily on economic outcomes" (Diener and Seligman 2004), our findings suggest that policymakers should also pay attention to SWB when managing outmigration, at least for rich countries. On the other hand, as many poor countries are still trying to fulfill basic needs of life, a focus on SWB may not be efficient in terms of managing emigration. Besides policy implications, our findings should encourage researchers to devote more attention to the potential for SWB to explain human behavior in addition to using economic measures alone.

\section{Endnote}

${ }^{1}$ Life satisfaction has been used interchangeably with SWB in some studies. Although SWB covers more components than life satisfaction, such as happiness and positive affect, "life satisfaction was the most consistent and stable variable" among them (Diener 1984).

\section{Appendix}

\section{Appendix A: Alternative migration questions}

To test our result, we use a migration intention question: "In the next 12 months, are you likely or unlikely to move away from the city or area where you live?" to test our results. This question is expected to have a stronger migration desire than the original one we used. And we found that migration intention also follows a downward trend as SWB increases (Figure 4A). Since this intention question includes internal migration, we further use an international migration plan question: "Are you planning to move permanently to another country in the next 12 months, or not?" This question is asked only if the respondent has international migration desire. To make the probabilities of these questions comparable (so that they can be included in the same graph with migration desire and migration intention curves), we multiply the conditional probabilities of having an international migration plan for the respondents with international migration desires by the probabilities of having an international migration desire, and obtain the adjusted probabilities of international migration plan for the whole sample. We observe that the adjusted probabilities of international migration plan also follow a downward trend (Figure 4A), the conditional probabilities of international migration plan for respondents with international migration desires are relatively stable, at least for respondents with near-average SWB scores (Figure 4B).

\section{Appendix B: Discussions of the limitations}

We list several limitations of our approach in the main text. Here, we justify that the main conclusion of the paper is not affected much by these limitations. 


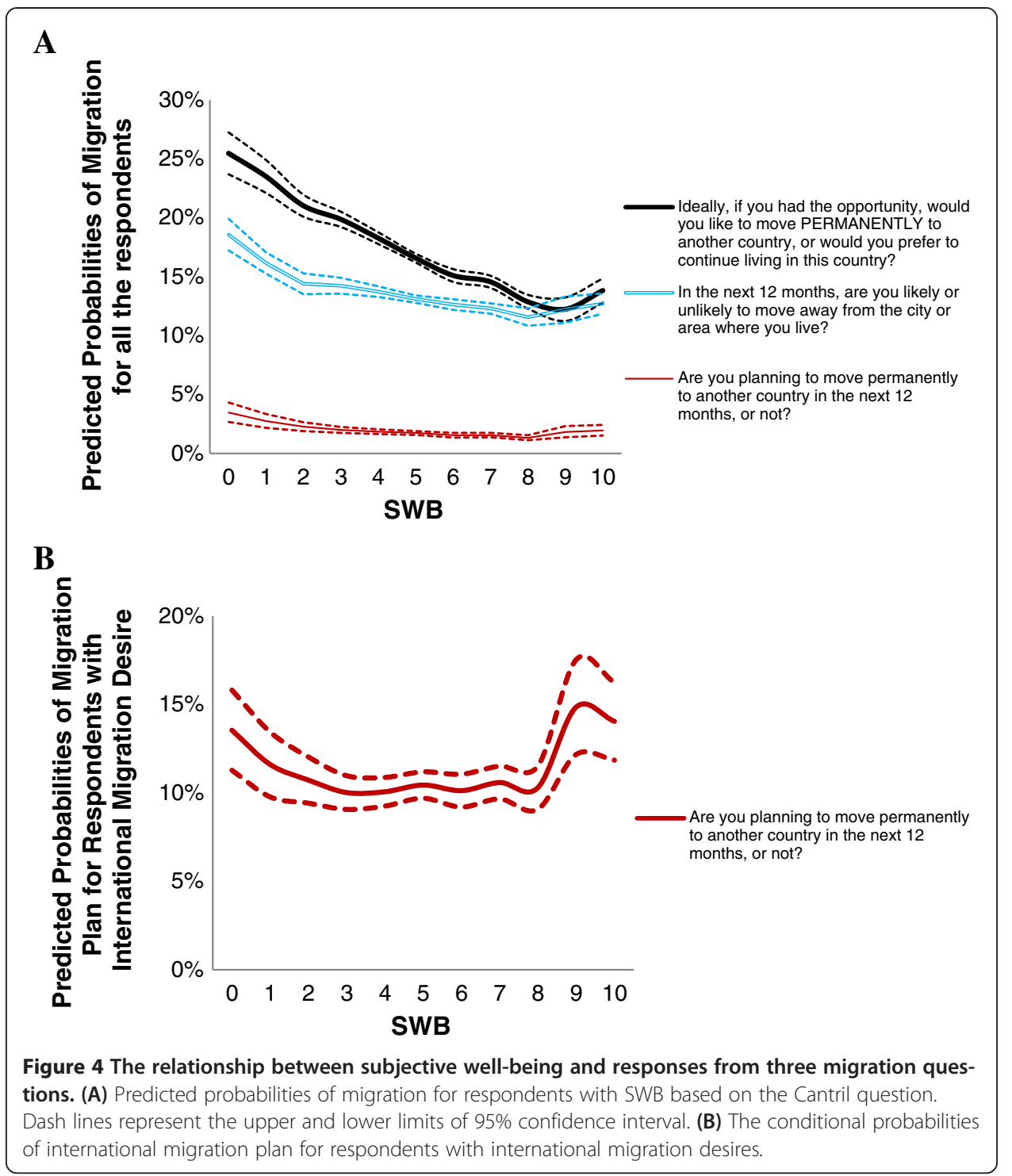

Limitation 1: We excluded the respondents who refused to answer the question or don't know the answer. It is possible that these respondents have different distributions of characteristics compared to others, which may cause bias.

Justification 1: By analyzing histograms of age for three groups of responses - Yes/ No response, Refuse/Don't Know response, and missing data, we find that only 2.86\% of respondents have Refuse/Don't Know responses, as compared to $97.14 \%$ of respondents having Yes/No responses to the desire to migrate question. Also, only $0.88 \%$ of respondents have Refuse/Don't Know responses, as compared to $99.12 \%$ of respondents who provide a SWB level. Therefore, main conclusion should still hold under this limitation.

Limitation 2: SWB may be affected by events happening before interview (Krueger and Schkade 2008).

Justification 2: Events or previous survey questions may cause bias in individual responses, but it is expected to be unbiased for aggregate responses from many 
respondents, since these events should have equal chance of increasing or decreasing individual SWB. Also, the Cantril question is the first question asked during the Gallup interview, so there is no previous survey question.

Limitation 3: Alternative measurements of SWB, such as time use, have been proposed (Krueger et al. 2009).

Justification 3: life satisfaction is believed to be the major component of SWB (Diener, 1984). And we do find that using life satisfaction and the Cantril questions generate similar relationship between SWB and migration (Table 4). Using time use, for which data are not available to us, we expect to have similar results.

Limitation 4: Furthermore, there may be certain subjective differences in interpreting SWB and migration across different countries.

Justification 4: This is partially addressed by showing that our main results hold for most countries.

\section{Competing interests}

The IZA Journal of Migration is committed to the IZA Guiding Principles of Research Integrity. The authors declare that they have observed these principles.

\section{Acknowledgements}

We thank the Gallup Organization for the access to the Gallup World Poll. We also thank Angus Deaton and colleagues in Princeton University for helpful discussions and comments. We are especially thankful to the editor, Amelie Constant and to an anonymous referee for their helpful comments and suggestions. This research was supported by the Science, Technology, and Environmental Policy (STEP) program at Princeton University and the High Meadows Foundation.

Responsible editor: Amelie F Constant

\section{Author details}

1411 A Robertson Hall, Woodrow Wilson School of Public and International Affairs, Princeton University, Princeton, NJ 08544, USA. ${ }^{2} 502$ Carnegie center, Suite 300, Gallup Inc, Princeton, NJ 08540, USA. ${ }^{3} 448$ Robertson Hall, Woodrow Wilson School of Public and International Affairs, Princeton University, Princeton, NJ 08544, USA. ${ }^{4}$ Geosciences, Princeton University, Princeton, NJ 08544, USA. ${ }^{5}$ Room 715, School of Economics, Shanghai University of Finance and Economics, Shanghai 200433, China. ${ }^{6}$ Department of Economics, Chinese University of Hong Kong, Shatin, NT, Hong Kong.

Received: 21 February 2014 Accepted: 1 April 2014

Published: 7 May 2014

\section{References}

Bartram D (2011) Economic migration and happiness: comparing immigrants' and natives' happiness gains from income. Soc Indic Res 103(1):57-76

Borjas GJ (1989) Economic theory and international migration. Int Migr Rev 23(3):457-485

Bucchianeri GW (2007) Be It Ever So Humble: Understanding Housing Using Subjective Well-Being Data. Discussion paper series no. 588, School of Economics and Finance. In: The University of Hong Kong, Hong Kong

Cantril H (1965) The Pattern of Human Concerns. Rutgers University Press, New Brunswick, NJ

Cárdenas M, Di Maro V, Sorkin I (2009) Migration and life satisfaction: evidence from latin America. J Bus Strategy 26 (1):9-33

Chindarkar N (2014) Is subjective well-being of concern to potential migrants from Latin America? Soc Indic Res 115 (1):159-182

Clark AE (2001) What really matters in a job? Hedonic measurement using quit data. Labour Econ 8(2):223-242

Clark X, Hatton TJ, Williamson JG (2007) Explaining US Immigration, 1971-1998. Rev Econ Stat 89(2):359-373

Creighton MJ (2013) The role of aspirations in domestic and international migration. Soc Sci J 50(1):79-88

De Jong GF, Chamratrithirong A, Tran QG (2002) For better, for worse: life satisfaction consequences of migration. Int Migr Rev 36(3):838-863

Deaton A (2008) Income, health, and well-being around the World: Evidence from the Gallup World Poll. J Econ Perspect 22(2):53-72

Delhey J, Kroll C (2012) A "Happiness Test" for the New Measures of National Well-Being: How Much Better Than GDP Are They? Discussion Paper no. SP I 2012-201. In: Social Science Research Center, Berlin

Diener E (1984) Subjective well-being. Psychol Bull 95(3):542-575

Diener E, Seligman M (2004) Beyond money: toward an economy of well-being. Psychol Sci Publ Interest 5(1):1-31

Dolan P, Peasgood T, White M (2008) Do we really know what makes us happy: A review of the economic literature on the factors associated with subjective well-being. J Econ Psychol 29(1):94-122

Easterlin R (1974) Does Economic Growth Improve the Human Lot? Some Empirical Evidence. In: David P, Reder M (ed) Nations and households in economic growth: essays in honour of Moses Abramovitz. Academic Press, New York and London, pp 98-125 
Feng S, Oppenheimer M (2012) Applying statistical models to the climate-migration relationship. Proc Natl Acad Sci USA 109(43):E2915

Feng S, Krueger AB, Oppenheimer M (2010) Linkages among climate change, crop yields and Mexico-US cross-border migration. Proc Natl Acad Sci USA 107(32):14257-14262

Foresight (2011) Migration and Global Environmental Change: Future Challenges and Opportunities. Final Project Report. In: The Government Office for Science, London

Freeman RB (1978) Job satisfaction as an economic variable. Am Econ Rev 68(2):135-141

Goudie RJB, Mukherjee S, De Neve J, Oswald AJ, Wu S (2012) Happiness as a driver of risk-avoiding behavior. CEP Discussion Paper no. 1126 centre for economic performance, LSE.

Graham C, Markowitz J (2011) Aspirations and happiness of potential latin American immigrants. J Soc Res Policy 2(2):9-25

Kahneman D, Deaton A (2010) High income improves evaluation of life but not emotional well-being. Proc Natl Acad Sci USA 107(38):16489-16493

Kenny C (2011) Getting Better: Why Global Development is Succeeding and How We Can Improve the World Even More. Basic Books, New York

Krueger AB, Schkade DA (2008) The reliability of subjective well-being measures. J Public Econ 92(8):1833-1845 Krueger AB, Kahneman D, Schkade DA, Schwarz N, Stone AA (2009) Measuring the Subjective Well-being of Nations: National Accounts of Time Use and Well-being. University of Chicago Press, Chicago, IL

Mansoor A, Quillin B (2006) Migration and Remittances: Eastern Europe and the Former Soviet Union. The World Bank, Washington $D C$

Massey DS, Arango J, Hugo G, Kouaouci A, Pellegrino A, Taylor JE (1993) Theories of international migration: a review and appraisal. Popul Dev Rev 19(3):431-466

Massey DS, Axinn WG, Ghimire DJ (2010) Environmental change and out-migration: evidence from Nepal. Popul Environ 32(2-3):109-136

Naudé WA (2010) The determinants of migration from Sub-Saharan countries. J Afr Econ 19(3):330-356

Oswald AJ, Wu S (2010) Objective confirmation of subjective measures of human wellbeing: evidence from the U.S.A. Science 327(5965):576-579

Otrachshenko V, Popova O (2014) Life (dis)satisfaction and the intention to migrate: Evidence from Central and Eastern Europe. J Socio Econ 48:40-49. DOI: http://dx.doi.org/10.1016/j.socec.2013.09.008

Park N (2004) The role of subjective well-being in positive youth development. Ann Am Acad Polit Soc Sci 591(1):25-39

Pedersen PJ, Pytlikova M, Smith N (2008) Selection and network effects - migration flows into OECD countries, 1990-2000. Eur Econ Rev 52(7):1160-1186

Polgreen L, Simpson NB (2011) Happiness and international migration. J Happiness Stud 12(5):819-840

Simpson NB (2013) Happiness and migration. In: Constant AF, Zimmerman KF (ed) International handbook on the economics of migration. Edward Elgar Publishing, Cheltenham, UK, pp 393-407

Stark O, Taylor JE (1989) Relative deprivation and international migration. Demography 26(1):1-14

Stevenson B, Wolfers J (2008) Economic Growth and Subjective Well-Being: Reassessing the Easterlin Paradox. In: Brookings Papers on Economic Activity, pp 1-87

Stevenson B, Wolfers J (2013) Subjective well-being and income: is there any evidence of satiation? Am. Econ Rev 103(3):598-604

Van Dalen HP, Henkens K (2008) Emigration Intentions: Mere Words or True Plans? Explaining International Migration Intentions and Behavior. In: CentER Discussion Paper no 1. 2008-60 Tilburg University, Tilburg

Van Dalen HP, Henkens K (2013) Explaining emigration intentions and behavior in the Netherlands. Pop Stud 67(2):225-241

doi:10.1186/2193-9039-3-8

Cite this article as: Cai et al: International migration desires related to subjective well-being. IZA Journal of Migration 2014 3:8.

\section{Submit your manuscript to a SpringerOpen ${ }^{\circ}$ journal and benefit from:}

- Convenient online submission

Rigorous peer review

- Immediate publication on acceptance

- Open access: articles freely available online

- High visibility within the field

- Retaining the copyright to your article

Submit your next manuscript at $\boldsymbol{\sim}$ springeropen.com 